\title{
Collaboration, Questioning and Encouraging to Foster Critical Thinking
}

\author{
Selma Belhamidi \\ English Department, University of Badji Mokhtar, Annaba, Algeria
}

\begin{abstract}
Learning involves the use of several types of thinking as critical thinking (CT) which is believed to be the output of a good education; it is also an indispensable part of it because being able to think critically is necessarily a condition for being educated. However, EFL teachers at the middle level (ML) are confronted to their learners' underdeveloped ability to think. Paradoxically, the curricula of English (and other subject matters) at all levels of the new education system in Algeria focus on developing the learners' CT skills[18]. This article displays the results of an experimental research where a treatment implemented for seven terms shows the effect of collaboration, questioning, and encouraging young adolescents to think at a higher level as it helps EFL teachers to create an active effective reflective environment in which young adolescents' CT abilities are stimulated.
\end{abstract}

\section{Introduction}

In order to be ready to participate effectively and actively in society, young adolescents need to live experiences that prepare them for life during which they take several decisions that may deeply change their existence. However solving problems and taking decisions require higher level thinking. The latter is the obvious outcome of a good education [4] [13] [20] [21]. By 'good education' we refer to a system based on methodologies that educate minds and not only store them with facts.

Most modern scholars and researchers objected to the line of reasoning which states that pupils must master the lower level thinking skills as comprehension (according to Bloom's Taxonomy) before they can engage in higher order thinking. Recent cognitive research challenges that assumption, and that higher order thinking can be practised even in schools elementary schools.

Moreover, he considers CT as an evaluative operation built on understanding facts and the importance of examining the grounds or evidences that
In this work, CT is considered as the product of a good education. It is briefly defined as doubting and seeking truth. It is essential for personal, group and professional decision making, besides it is crucial for democracy. Thus we argue that it is necessary to develop this faculty since an early age. Classroom environment should reflect a cultural milieu that nurtures CT dispositions and provide young learners with opportunities to learn and practise CT skills. Such environment strengthens good thinking and teaching results in good thinkers; teachers have the unique opportunity to model effective techniques that result in not only good students but in lifelong learners and thinkers [14].

\section{Literature review}

The concept of CT we adhere to reflects a notion embedded in a large core body of research over the last 30 to 50 years. Yet a survey of the current literature about CT reveals a lack of unity in defining it. This can be attributed to the differing perspectives from which disciplines such as philosophy and cognitive psychology view CT. While philosophers emphasize 'critical thinking' and focus on the nature and quality of the products of critical thinking as the analysis of arguments; psychologists, on the other hand, emphasize the notions of 'skills' and 'dispositions' and concentrate on the process of cognition.

John Dewey views reflective thought, which is in his opinion the basis of the scientific method and the end of education, as an '[...] active, persistent, and careful consideration of any belief or supposed form of knowledge in the light of the grounds that support it and the further conclusions to which it tends. [...] it is a conscious and voluntary effort to establish belief upon a firm basis of reasons [4]'. So he stresses 'active' to characterize CT, as opposed to passive. By 'persistent' and 'careful', he is contrasts it to unreflective thinking; the kind of thinking we sometimes engage in when we take a quick decision. support any belief or knowledge. Furthermore, it is a non-random phenomenon that includes a 'sequence of ideas' in a 'consecutive ordering' where each step 
takes the next as its direct outcome [4]. Also contemporary philosophers [9] [20] share the same assumptions as Dewey.

On the other hand, Cognitive and experimental psychologies present a wider range of research on CT. They focus on the cognitive process, levels of thinking and factors promoting it. They view CT as a set of skills and dispositions. The Delphi Report (1990), which is a project sponsored by the American Philosophical Association's committee on Pre-College Philosophy, tried to reach experts' consensus on what CT is, how it can be assessed and what factors promote it. They could determine CT skills: interpretation, analysis, evaluation, inference, explanation and selfregulation; and resumed that a good critical thinker should be disposed to be analytical, open-minded, confident in reason, truth-seeking, judicious, inquisitive and systematic [8].

It is important to state that many researchers confirm eventually that CT skills can be taught and learnt through practice. They also view CT dispositions as any other traits of character that can be influenced by the environment; in which they should be nurtured. Therefore and since the 1980's, there has been a broad consensus and a growing accord among scholars who called for the integrating of CT instruction in the middle and college curricula as in the university; this is for the sake to make of the learners skilful people ready to meet the challenges of the new world which is shaped by globalization and controlled by media.

This study is concerned with enhancing young adolescents' CT abilities. However one may wonder first about their readiness; to what extent are they ready to think at a higher level? According to Piaget, by the age of 12, young adolescents cognitive development moves to a 'Formal Operational stage' where they progressively develop more complicated thinking abilities 'Hypothetical-Deductive Reasoning' that allows them to hypothesize, make inferences, compare or debate ideas and to derive conclusions to more abstract problems [12].

Piaget explains that by using hypotheses, the YA can adopt the other's view point and draw reasonable consequences it implies and then judges its significance. Secondly, he will show interest in problems and questions that go beyond his field of experience. Henceforth, he is able to understand theories, to play a role in society where he lives, to adopt ideologies and usually he wants to change society for better living conditions. Besides, the ability to consider possibilities and facts may have an influence on the YA's decision making in either a positive or negative way. This transition from lower to higher thinking requires support without which the young adolescent finds it difficult to solve problems real to life. This support should be provided by their families, teachers, and techniques used in class [10] [11] [12].

Furthermore, Vygotsky believes that this life long process of development is dependent on social interaction and that cooperative learning actually leads to cognitive development. This phenomenon is called the Zone of Proximal Development (ZPD). Vygotsky describes it as 'The distance between the actual development level as determined by independent problem solving and the level of potential development as determined through problem solving under adult guidance or in collaboration with more capable peers' [22]. It defines those functions 'intellectual operations' which are not yet matured but under the process of maturation and that will mature tomorrow. The Zone of Proximal Development is the gap between what is known and what can be known.

In school environment, some factors are necessary to foster CT. A teaching centred on the learners and engaging them in active learning can provide them with opportunities to learn and practice CT skills meanwhile their dispositions to think critically are nurtured. Actually, an encouraging environment should probably not reflect neither too much structure nor too little. It should be stimulating indeed; different interaction patterns can be used, changing the seating provides learners with more opportunities to meet different people and to exchange ideas and opinions, varying materials challenges learners observation skills and prompts them with more practice of their CT skills. Experimentation, questioning, discussion and discovery usually create effective learning opportunities and make of the environment in the classroom more challenging and interesting where the teacher plays an important role. Furthermore textbooks, syllabi and curriculums should be designed to foster CT.

Recently specialists in teaching English as a foreign language and didactics agree on the important impact of collaboration on learning. It creates equal learning opportunities for all learners while working together which makes learning meaningful, besides it creates a suitable environment for decision making. Additionally it reduces anxiety and helps learners develop social skills that facilitate their integration in their communities later [2] [3] [9] [11] [14] [16] [22].

It is believed that CT involves asking questions, thus questioning remains an effective technique to boost the latter [1] [3] [7] [11]. Asking relevant and challenging questions in class stimulates thinking and provides young learners with training for their minds. Even if they are different and grow at different speeds but questioning creates the necessary change, challenge and makes learning more effective.

Thinking at a higher level is not an easy task for young adolescents; they need to be encouraged [5] [6] 
[15]. Encouraging learners to observe perpetually, to ask questions, to make inferences, to give their opinion and support it with arguments, to give justifications for a choice they make, to be open minded, to be truthseeker, etc. boosts their CT dispositions and skills; hence their level of cognition grows rapidly. Generally an encouraging attitude follows six practices:

- Make relationships a priority

- Conduct respectful dialogue

- Practise encouragement daily

- Make decisions through shared involvement (Inside/outside classroom meetings)

- Have fun

- Resolve problems on regular basis [16].

The paper displays a part of the results of a longitudinal study (preceded by a survey) on the importance of questioning, collaboration and encouraging in creating an active effective reflective environment necessary to nurture young adolescents' CT abilities. We adopt a mixed methods paradigm (quantitative/qualitative) type three: experimental qualitative - interpretative that recommends the use of an experiment but provides qualitative data which are analysed interpretively besides quantitative data collected through the Posttest-Only Design with Nonequivalent Comparison groups.

Participants are young adolescents (11-15 years) who have been under investigation for eight terms (January 2010 - March 2012). Two groups of 32 pupils (experimental and control) from the same school were chosen. We make use of naturalistic observations, tests, a formative evaluation and Cornell Class Reasoning Test CCRT (Cornell Class-Reasoning Test, Form X, a multiple-choice deductive logic classreasoning test written by Robert $H$. Ennis and published by Illinois Critical Thinking Project). CCRT provides us with quantitative data at the end of the treatment.

Results show that a teaching based on collaboration, questioning and encouraging learners to think at a higher level boosts their CT skills. It also nurtures their disposition to think critically; subjects show more inclination toward open-mindedness, inquisitiveness, truth-seeking, curiosity, etc.

\section{Method}

During the pre-treatment phase (Term 1), a survey was undertaken. A questionnaire was administered to EFL teachers, the textbook of English for year four in the ML was analysed and an observation practice was followed for the aim to investigate and report the reality of the learning situation in the EFL class at the middle level concerning mainly the deficiency in nurturing $\mathrm{CT}$.
The survey revealed that EFL teachers are conscious of the importance of the learning environment that should be active since they deal with young adolescents. However, in their daily work, they focus on some factors necessary to teach English as a second foreign language; yet teach to test overwhelms their work. Thus they give fewer opportunities for learners to think at a higher level; they focus more on whole and individual work than collaborative learning for example. Moreover EFL teachers do not use suitable classroom techniques necessary to foster CT; questions asked remain at a low level of cognition according to Bloom's Taxonomy, they also avoid learners' open questions, etc.

Besides this the textbook for English does not help EFL teachers to promote CT in their classes; only a few instructions asked learners to use higher thinking order. It does not encourage collaboration; it lacks pedagogic aids open to interpretation too. Yet scaffolding, evaluation, self-assessment and integrating knowledge are given importance.

In the light of the diagnostic phase results, which is meanwhile the pre-treatment phase, we make recourse to an experimental research where a treatment was implemented. We assume it creates an active effective reflective environment necessary to nurture $\mathrm{CT}$ in the EFL class or any other one. It is based on factors necessary to facilitate learning; they are collaboration, questioning and encouraging young adolescents to think at a higher level.

During the second phase or the while-treatment phase which lasted for seven terms (April 2010-March 2012), we had been a participant observer to be fully engaged as part of the group in order to manage the experiment and to be familiar with what the participants were experiencing during the session and outside. In the participant observation, which is believed to be '[...]an observational method in qualitative research that uses the five senses to describe the (a) setting, (b) people, (c) occurrences, and (d) meaning of what was observed. In other words, it examines the intricacies and relationships of individuals [17]'; notes on physical behaviours, spoken and unspoken communication venues, activities, and interactions were taken besides our own observations.

The reason behind being near the participants is to witness the changes since it is argued that changes at the cognitive level are better observable in natural environment and in subjects' achievements both oral and written. Observations are usually recorded using the mobile phone after class. Data from learners' achievements: formative and final evaluations, integrating situations, projects are also collected. Moreover oral data are collected from real situations of work and conflicts. Remarks from discussions with 
teachers in the staff room are taken into consideration too.

The post-treatment phase is devoted to numerical data collection to confirm or reject the naturalistic observation results and the hypothesis which states that an active effective reflective teaching based on: collaboration, questioning and encouraging nurtures YAs' CT dispositions and skills. Numerical data is collected through CT tests.

The CT test we provide learners with is the CCRT. Yet what is worth to mention here is that this test, as confirmed his owner Dr. Ennis, is a test covering only one aspect of CT since it tests for a variety of forms of deduction concerning class reasoning. Originally the test contains 80 multiple choice questions but subjects are asked to answer only 50 .

The CCRT supplies us with quantitative data that may add more clarification to the qualitative ones collected through naturalistic observation. Nevertheless we think that the CCRT does not really translate the effectiveness of the treatment then we provide subjects with another test, BEM evaluation (a national final exam that learners must pass after four years at the ML, success allows them to move to the secondary school.) for year 2009 (see Figure 2). The objective is to assess subjects' abilities in paying attention to details and making inferences and their disposition to be judicious and systematic. This test is needed to generate more in depth information about the results. Both CCRT and BEM 2009 are done by control and experimental groups.

\section{Results and discussion}

It is necessary to the research and the naturalistic observation to describe the sample as empirically as possible before the treatment. Learners in both groups experimental (Exp.Gr) and control (Cr.Gr) listened more than they spoke; their utterances were short and never expressed more than simple needs. Also their questions were limited to spelling or handwriting. They really find it difficult to understand abstract words, nor even to guess meaning from context. Their observations were limited to descriptions.

Physically, learners were active, overwhelmed with shyness, not self-confident, not autonomous except for a very few learners who might have had better factors at home. Learners in this phase were not really able to concentrate. Moreover they found it difficult to do any activity that required reflection and giving their opinion, however; they could make a choice and express their preferences.

What is worth to mention is that boys used to sit aside and girls in another side of the classroom. Also when they were free to choose a partner to do a task, they chose a partner of the same sex. This may be due to their shyness which is natural at this stage of moral development; it can also be caused by the Algerian environment which usually favours this kind of discrimination.

In this period, another phenomenon was observed; disrespect characterized relations amongst learners either towards each other or toward their teachers. Some were even violent; they used to fight daily and often for ridiculous reasons. They fought while playing or practicing sport, some could even hit a friend to express excitement or happiness! Though this phenomenon is not new to the reader and it is not specific to only this group.

\subsection{Results of the participant observation}

As mentioned before, a participant observation was followed for the sake to observe changes at the cognitive level in a natural environment. The whiletreatment phase which lasted for seven terms was divided into three periods:

During the first period (January 2010 - May 2010), subjects were enrolling in second year at the ML during which we focused more on collaboration. Subjects in Exp.Gr were usually asked to do tasks in pairs and others in groups. They used to be noisy and disturbing. Some did not participate and relied on others to do the work for them, others felt embarrassed because they preferred to work individually. Also boys found it difficult to work with girls and preferred to work with male mates, same thing for the girls. Yet conflicts were resolved without any oppression; most of the time subjects were given freedom and their behaviours were redressed smoothly.

Actually it took more than a month to settle rules for collaboration or 'cooperation competences' [19]. Collaboration was emphasized not only inside the classroom but also outside as subjects had to work in groups to prepare projects on different topics; their work was monitored without much interference. However this does not mean that subjects did not perform individually.

As far as encouragement is concerned, subjects were daily supported to produce even little, to collaborate and cooperate with others even if noisy, to accept making mistakes as part of learning. They were also encouraged to practise their personal abilities as acting, writing poems, telling jokes, singing, dancing, etc. Moreover they were encouraged through freedom; they were free to choose members of the group, to agree on dividing tasks and responsibilities, the way they prepared the project and how to present it. However this was not as easy as one may imagine, subjects -when given freedom - used to frequently quarrel and to disagree mainly at the beginning. For example stronger subjects imposed tasks on weaker 
ones, most confident learners claimed that they found it hard to work in groups and preferred to work individually whereas lazy ones relied on others, etc.

A third element focused in the treatment remains questioning. During this period, subjects' questions did not express more than simple needs so they were usually encouraged to ask questions during the lesson; redundant and simple questions, mistakes and use of mother tongue (which is Arabic) were accepted.

Questioning as an effective technique in developing thinking was used at two levels:

-Throughout teaching process: we frequently asked subjects questions as:

What?

How?

Why?

What if?

-Using challenging questions when possible provided learners with opportunities to discuss, to share ideas, to interact, to listen to each other and to give their opinion. They were exposed to activities that stimulated higher thinking through which Bloom's Taxonomy for higher thinking order was used; subjects were asked to do actions such as: listing, describing, retrieving, naming, locating, interpreting, exemplifying, summarising, inferring or deducing, classifying, comparing, explaining, completing meaning, carrying out, changing, using, organising, deconstructing, integrating, checking, judging and giving opinion, assessing, guessing, monitoring, designing, planning, making, producing. Throughout these activities subjects realised different projects as: writing illustrated stories and short plays, designing plans, reporting, interviewing, investigating, making simulations and presentations, advertising, preparing a school magazine, etc. This was implemented gradually during the course of the seven terms.

The second period (September 2010 - May 2011) concerns terms three, four and five of the treatment; learners were enrolling in the third year at the ML. In this period we continued using collaboration, questioning and encouragement. By the third term, it was clear that subjects were more active and challenged except those who were really shy and silent; they simply needed much more time, our attention and help. Yet it is important to mention here that learners whose learning style seemed to be reflective showed more advancement at the level of reflection; more concentration was noticed, they also asked for and gave justifications. Besides they expressed their opinion and provided some arguments and examples to support it. They also asked for rules to make generalizations concerning mainly grammar and pronunciation. We observed that they were more selfconfident too.
Furthermore it was noticed that subjects respected each other, there were fewer problems and there were more friendships between boys and girls. They felt less embarrassed when sitting or working with another subject of a different sex, except for very few of them who had religious inclinations. Good contacts were not only seen in class but also in the hall, or the yard at the break time. They used to stand in small or larger mixed groups, they laughed and they chatted which was not the case in other groups. This was also observed while preparing their projects; they usually exchanged ideas and helped each other to achieve their tasks.

As far as questioning is concerned, during sessions in this term, different questions were asked; some subjects asked for clarifications and alternatives for example:

- What if we put (x) at the place of $(y)$ ?

- What can we put at the place of $(\mathrm{x})$ ?

- Why did we do this or that in this example?

- Why and what for?

Moreover, they were less ashamed to make mistakes. Other positive behaviours were depicted too. In many situations subjects showed open-mindedness and made fewer prejudices concerning: love matters, dressing way and differences in personal traits. They also claimed for their rights.In fact an active effective reflective environment was created as suggested in this experimental research.

Yet at the beginning of the fifth term, some unexpected negative behaviours appeared; some learners seemed less confident and asked usually for the teacher's opinion or the help of their friends. So we decided to redirect encouragement via auto-evaluation and peer-evaluation. This was achieved by encouraging them to seek weaknesses in their own works and to try to correct them alone. By the end of the term, many subjects have changed their behaviours and attitudes towards collaborative work and questioning.

Furthermore, collaboration resulted in another negative behaviour; some subjects became stronger. They formed clans; they used to help each other even by cheating in tests. They were more self-confident and rebellious, they usually disturbed their teachers mainly authoritarians- and mocked at them though they were good learners, active and hard workers as attested by all the staff teaching this group.

During the fifth term, subjects were engaged in different activities to prepare for a school celebration the researcher was the responsible. They were free to prepare the way they wanted; writing poems or stories and preparing for a school magazine, singing, acting, showing magic tricks, telling jokes, reciting Koran, preparing for competitions in cooking, drawing, writing poetry, handcrafts, to prepare projects and creations in all subject matters. The aim was to depict CT skills in their achievements and to assess their 
decision making in a natural learning environment; mainly in work and conflict situations.

In fact this active environment helped the participants to discover their and their friends' abilities and hobbies. It also provided them with opportunities to practise higher order thinking as problem solving and decision making, besides fewer troubles between them were noticed.

Observations made out of the subjects' achievements divulged some advancement in giving opinion, making analogies, observing and paying attention to details, making judgements and comparisons, etc.

The third period (September 2011 - March 2012) included terms six and seven of the treatment, pupils enrolled at the fourth level. This period was transitional between the while and the post treatment phases. We carried on the daily contact with subjects through participant observation. The aim was to assess CT since it is argued it is better assessed through naturalistic observation and after it should be confirmed by tests or subjects' written assignments.

During this time, subjects -mainly reflectors- asked more complex questions. They usually asked for more precision and further details. They were able to notice contradictions in the lesson, in an explanation given, or to depict an inadequacy in the textbook. They noticed more differences between English learnt in class and what they could find in books, dictionary, TV or internet. They asked for rules to make generalizations and they usually showed signs of curiosity and searching for details. They also made analogies as they could find similar features in comparing different things: languages systems, texts, activities and people.

Furthermore those learners brought knowledge to class; they used to freely make investigations. A few used this to trick their teachers who felt challenged but embarrassed; they frequently claimed that at the end of term six.

An important fact was noticed; subjects remembered and recalled easily language points and vocabulary seen in the first period of the treatment. We think it is due to the active effective reflective learning environment in which learning English occurred. It is largely argued that learning that occurs in cooperative, active and funny environment is better acquired and well-remembered [22].

Nevertheless some subjects did not show a noticeable advancement at the cognitive level, but this does not mean that they were not developing. Piaget asserts that even in favourable environments, which stimulate intellectual growth, some individuals have different 'aptitudes' that change progressively with age. Thus their cognitive development takes much more time than other individuals [12] [22].
Notes collected from other teachers of the Exp.Gr confirm that the treatment had a positive impact on learners' level of thinking. Their comments prove the observations displayed above. They clearly asserted that learners in the Exp.Gr were active, hard workers, inquire about information given, ask content provided in class and asked for further details, some made research voluntarily and brought information and more explanation to class. This also confirms the effectiveness of the treatment implemented. Yet to obtain more reliable results, numerical data is needed.

\subsection{Results of CT tests}

A sample of 15 copies of the CCRT for each group (control and experimental) are scored and analyzed, results are shown in Figure 1, which contains also a table showing the results obtained by subjects in both Exp.Gr and Cr.Gr.

Generally speaking, results obtained are not satisfactory for both groups (Exp.Gr and Cr.Gr ) except for one subject who could obtain 36 out of 50. Yet this is justifiable since subjects seemed really tired because they had just started revising for the BEM exams and most spent sleepless night. Despite appropriate time given for the test, subjects in both groups did not manage well.

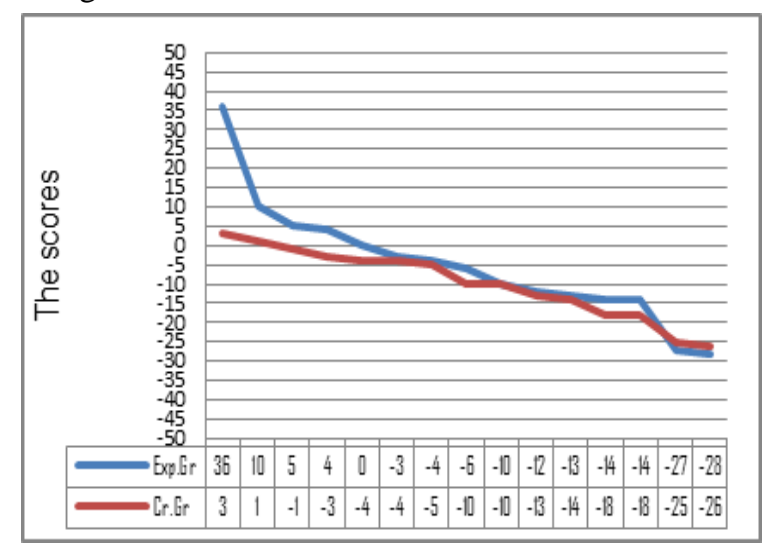

Figure 1. CCRT results

However the curve shows that subjects in Exp.Gr managed slightly better in the test which is covering only one aspect of CT since it tests for a variety of forms of deduction concerning class reasoning. Actually this justifies the naturalistic observation results but does not confirm them. So results obtained by another test (formative evaluation) are analyzed.

Concerning the modified BEM 2009, it was given to subjects as a formative evaluation Figure 2. Pupils ignored that they would be evaluated on specific criteria. In the integrating situation, the instruction is modified; 'Do you agree or disagree with children's 
work?' and 'justify your opinion, give your reasons and state some examples.' are added.

What if you had to work today?

A hundred years ago many children had to work. Some weren't even ten years old. Their workday was often sixteen hours long. These children never went to school. They had no time to play. They hardly ever got fresh air. How could this happen?

Some children had no mothers or fathers who could look after them. Others had to take care of their sick parents. Most were just helping their families earn money to live.

Many people worried about such children. They forced the people who made the laws to do something about this problem.

In 1916, a new law was passed. For the first time in the United States, young children were not allowed to have jobs in factories.

People today understand that children need to rest and play. They know too, that schoolwork is the best kind of "job" or young minds.

Part One:

\section{A-Reading Comprehension}

Activity One: Read the following statements and write "true", "false" or "not mentioned".

1)All the children had to go to school a century ago

2) It was hard for some parents to look after their children.

3)Parents who sent their children to work had problems.

Activity Two: Answer the following questions:

1)Did people feel concerned about children's work?

2)Were their actions against children's work unsuccessful?

Activity Three: Find in the text words or phrases that are closest in meaning to the following:

Were obliged $=\ldots \S 1 \quad$ The majority $=\ldots \S 2$

Not permited $=\ldots \S 4 \quad$ Relax $=\ldots \S 5$

B-Mastery of the Lanquage

Activity One: Supply the punctuation and capitals where necessary.

all children should have the right to education they also have the right to free medical care

Activity Two: Write the correct form of verbs in brackets. Years ago, children (to not have) go to school. Now there's a law: children must (to stay) at school till the age of sixteen. So, if some parents (to not respect) the law, they will be in trouble.

Activity Three: Find in the text four words that have the following sounds:

lail: $1 \ldots \ldots . .2 \ldots . . \quad$ lei/: $1 \ldots \ldots . \quad 2 \ldots \ldots$

Part Two: Integrating situation

A lot of children, in the world, do not go to school because they have to work to help their parents.

You feel concerned about this problem. Do you agree or disagree with children's work?

Write an article for your school magazine about this problem. Justify your opinion, give your reasons and state some examples.

These hints can help you:

children's protection (education/health/food...)

-children's leisure (games/sports...)

\section{Figure 2. Formative evaluation}

Both Exp.Gr (32 subjects) and Cr.Gr (32 subjects) have passed the test. Table 1 shows the results. First, results gathered by the formative evaluation show that subjects in Exp.Gr obtained better results since 24 out of 32 got more than 10 out of 20 points which represents $75 \%$ of the target population. In contrast half subjects in control group could reach the average.

Table 1. BEM 2009 results

\begin{tabular}{|c|c|c|c|}
\cline { 2 - 4 } \multicolumn{1}{c|}{} & +10 & $\%$ & Mean \\
\hline Exp.Gr & 24 & $75 \%$ & 12,14 \\
\hline Cr.Gr & 16 & $50 \%$ & 10,33 \\
\hline
\end{tabular}

Nevertheless the mean which is the overall average response translates a better achievement in the test for the experimental group 12, 14. This logically interprets an accepted achievement from the majority of the subjects at the three levels of the test: reading comprehension, mastery of the language and the integrating situation. Nevertheless this is not enough to confirm the results of the naturalistic observation.

Essentially subjects are evaluated at the level of two skills of CT: paying attention to details and making inferences. For this reason, only activity one and activity two in section one of the test are concerned with the analysis. In addition to that the integrating situation is examined and subjects' abilities to deduce and to explain are assessed, besides their disposition to be systematic and judicious.

In activities one and two of the test, subjects are asked to make inferences as information sought is not given directly in the passage. Figure 3 illustrates the results to activity one where subjects are asked to say if the statement is true, false or not mentioned. Correct answers are (1) false, (2) not mentioned, (3) true. Information is given indirectly in the passage, learners have to read for details, link information to make an inference and decide finally if the statement is correct, false or not mentioned in the text.

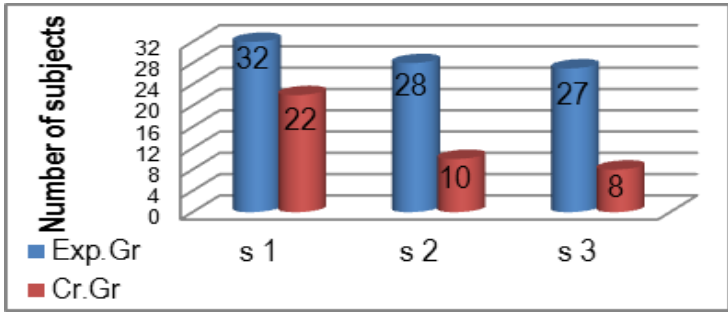

\section{Figure 3. Evaluation results for activity one}

Statement one assesses subjects' ability to pay attention to details and to concentrate. The figure shows that all members of the Exp.Gr could concentrate and pay attention to the detail 'work' 
rather than 'school' whereas in the Cr.Gr only 22 noticed the detail in paragraph one.

Statement two in the same activity expresses some ambiguity; subjects have to read carefully in order to find details to decide if the statement is false or not mentioned. In nearly the same level of ambiguity in statement three, subjects have to find the right information to infer that parents who sent their children to work had problems. For both statements (two and three) subjects in the Exp.Gr managed better and have better results (28 and 27) while subjects in the Cr.Gr found it difficult to relate information to make inferences to make the right judgment.

In activity two, subjects have to answer comprehension questions about the text. Although they are auxiliary questions, but they require scanning carefully the text and linking information to make the right judgment and decide to say either 'yes' or 'no'. Results are shown in Figure 4 below; subjects in both groups could infer the right answer for question one yet more subjects in Exp.Gr (28) answered correctly this question than Cr.Gr (15).

Concerning the second question which is more ambiguous since learners have first to read for details and relate information to decide, besides the prefix in (unsuccessful) created some ambiguity for the subjects in both groups. However, more subjects in Exp.Gr (15) answered correctly this question than Cr.Gr (9).

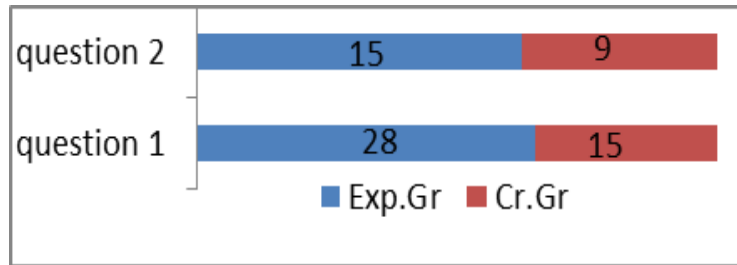

\section{Figure 4. Evaluation results for activity two}

Results represented by both Figures 3 and 4 show that subjects in the experimental group express better abilities in reading for details and making inferences in order to make correct and logical decisions based on justified judgments.

As far as the situation of integration (in the test) is concerned, subjects are asked to write an article for their school magazine about children's work. They have to express agreement or disagreement, to justify their opinion and to support it with reasons and examples.

Written assignments are corrected. For some learners, English as a foreign language was a major impediment that disabled them from expressing their ideas. Does this mean that they did not develop CT skills or did not show a disposition to think critically?
In the integrating situation, subjects' dispositions to be judicious and systematic are assessed. In this assessment, subjects' abilities to deduce and to explain are assessed too. Results are displayed in Table 2.

\section{Table 2. Assessed skills}

\begin{tabular}{|c|c|c|c|c|}
\cline { 2 - 5 } \multicolumn{1}{c|}{} & To explain & To deduce & $\begin{array}{c}\text { To be } \\
\text { judicious }\end{array}$ & $\begin{array}{c}\text { To be } \\
\text { systematic }\end{array}$ \\
\hline Exp.Gr & $56 \%$ & $60 \%$ & $23 \%$ & $70 \%$ \\
\hline Cr.Gr & $32,5 \%$ & $25 \%$ & $10,5 \%$ & $37,5 \%$ \\
\hline
\end{tabular}

It could be said that subjects in the experimental group show higher competence in giving explanations, deducing and to be more systematic but less judicious, whereas the Cr.Gr subjects seem to be less competent at the level of both CT skills and dispositions.

\subsection{Interpretation of the results}

Reflections and comments made during the naturalistic observation are confirmed by the CCRT and the formative evaluation done in the post-treatment phase. Results indicate that collaboration; questioning and encouraging YAs to work in groups and pairs, to answer open ended questions, to inquire about facts and opinions surrounding them, to search and work outside the classroom, etc. had nurtured their disposition to think critically.

Subjects in the experimental group show more inclination toward open-mindedness, inquisitiveness, truth-seeking, curiosity, and to be systematic. Their abilities to pay attention to details and to deduce are also nurtured. Furthermore social competences developed; they made fewer prejudices and gender difference disappeared gradually. More rationality is noticed but not for all subjects. Some subjects even demonstrate an intellectual courage.

Nonetheless a hardly distinguished positive impact on learners CT skills as self-assessment, examining ideas, clarifying meaning, etc. is noticed. Their disposition to be judicious did not clearly promote because (at this age) YAs show too much sensitivity so usually their feelings disturb their reasoning.

Yet it is necessary to clarify that only few learners' cognitive level clearly increased, many of them develop slowly and a few learners do not show any proliferation toward higher level thinking. This does not mean that they are not developing, but they develop at different rates because of many factors according to many researches in cognitive psychology.

It is evident from this experimental research that an active effective reflective environment provides 
learners with opportunities to train their minds. However this may give better results with reflectors; what about the other learners with several learning styles? Varying class activities may help EFL teachers to provide learners with much more opportunities to practise critical thinking skills and to nurture their dispositions to think critically in respect to their differences.

\section{Conclusion}

To sum, CT takes time to develop and it promotes in response to involvement in a specific cultural milieu. The cultural milieu that best nurtures thinking dispositions is referred to as the culture of thinking an environment that strengthens good thinking and results in good thinkers even if not well-acknowledged. That environment should be created inside the classrooms, outside and at home too.

This study divulged that an active effective reflective environment of learning where questioning, collaboration and encouragement are fostered has a positive influence on learners CT skills and nurtures their dispositions to think critically. The result is lifelong learners who learn consciously, doubt, inquire, and search for details to reach fair-mindedness which is the outcome of a good education that produces not only lifelong learners but good thinkers too.

\section{References}

[1] A. King, (1995). "Designing the Instructional Process to Enhance Critical Thinking Across the Curriculum", Teaching of Psychology, http://books.google.dz/books (8 august 2011)

[2] A. L. McGuire, "Improving Student Critical Thinking and Perceptions of Critical Thinking Through Direct Instruction in Rhetorical Analysis. A published dissertation for the degree of $\mathrm{PhD}$. Capella University.UMI 3408479, USA: Proquest LLC, 2010.

[3] Coil, C., Teaching Tools for 21 $1^{\text {st }}$ Century, Pieces of Learning, USA, 2005.

[4] Dewey, J., How We Think, MA: DC Heath, Boston, 1910.

[5] Dreikurs, R., B. Grunwald, and F. Pepper, Maintaining Sanity in the Classroom, Harper \& Row, New York, 1982.

[6] Evans, T., The Art of Encouragement, University of Georgia, Center for Continuing Education, Athens, 1989.

[7] F. L. Fisher, "Influence of Reading and Discussion on the attitudes of $5^{\text {th }}$ Graders Toward American Indians", The Journal of Educational Research, Francis and Taylor, UK, 1968, pp. 130-134.
[8] Facione, P. A. (1990). 'The Delphi Report'. The California Press; http://www.insightassessment.com (10 March 2010)

[9] Fisher, A., Critical Thinking: An Introduction, Cambridge University Press, UK, 2001.

[10] Gibson, R.K., C. A. Peterson, Brain Maturation and Cognitive Development: Comparative and Cross-Cultural Perspective, Library of Congress, USA, 1991.

[11] Hargreaves, A., L.M. Earl, and J. Ryan, Schooling for change: Reinventing Education for Early Adolescents, The Falmer Press Teachers' Library, NY, 1996.

[12] J. Piaget, "Intellectual evolution from adolescence to adulthood", Adolescent behavior and society: A book of readings, Random House, New York, 1980.

[13] James, W., Talks to Teachers on Psychology: And to Students on Some of Life's Ideals, Henry Holt and Company, New York, 1899.

[14] Johnson, N.L., Thinking is the Key: Questioning Makes the Difference, Pieces of Learning, OH: Beavercreek, 1992.

[15] Kohn, A., Beyond Discipline., Association for Supervision and Curriculum Development, Alexandria, 1996.

[16] L. R. Oxford, "Cooperative Learning, Collaborative Learning, and Interaction: Three Communicative Strands in the Language Classroom”, The Modern Language Journal, National Federation of Modern Language Teachers Associations, USA, 1997, pp. 443-456.

[17] Lunenburg, F. C., B. J. Irby, Writing a Successful Thesis or Dissertation, Corwin Press, USA, 2008.

[18] N. Toualbi-Thaâlibi, "Changement Social, Représentation Identitaire et Refonte de l'Education en Algèrie", La refonte du système éducative, Casbah Edition for O.N.P.S, Algérie, 2005, pp. 19-32.

[19] P. Chevalier, "Les Tice au Service de la Réforme. Action de Terrain au Service d'un Projet Durable ". Réforme de l'éducation et innovation pédagogique en Algérie, PARE: UNESCO-ONPS, MEN : Algérie, 2006, pp. 125-170.

[20] R. Ennis, A taxonomy of Critical Thinking Dispositions and Abilities, Teaching Thinking Skills: Theory and Practice, W.H. Freeman, New York, 1987, pp. 9-26.

[21] R. Ennis, "Critical Thinking Assessment", Teaching for Higher Order Thinking: Theory into practice, The Ohio State University, USA, 1993, pp. 179-186.

[22] Vygotsky, L.S., Mind and Society: The Development of Higher Mental Processes, Harvard Press, UK, 1978. 